\title{
A experiência da cor-luz: um ambiente cênico de Hélio Oiticica para um show de Gilberto Gil
}

The light-color experience: Hélio Oiticica's environmental scenography for a show of Gilberto Gil

Cássia Maria Fernandes Monteiro ${ }^{1}$ 


\section{Resumo}

Neste artigo podemos investigar de que maneira a cor-luz e os aspectos vivenciais da performance contribuem ao percurso poético do artista Hélio Oiticica durante a criação da ambientação cênica do show Gilberto Gil in Concert realizado em Nova lorque [1971]. Como eixo conceitual buscamos suporte nos estudos da cor de Wassily Kandinsky, no conceito de iluminação cênica de Denis Bablet e no traçado poético dos escritos de Oiticica. A partir dos documentos iconográficos, considerando a interlocução estética decorrente do momento tropicalista, pretendemos esclarecer de que maneira neste show a materialidade do som, da luz e da cenografia ativam a imagem para a participação vivencial no ambiente.

Palavras-chave: Hélio Oiticica; cor-luz; ambientação cênica

\section{Abstract}

On this article we can investigate how the light-colour and the experience aspects could contribute to Hélio Oiticica's visual poetry during the creation of an environmental scenography for the show Gilberto Gil in Concert held in New York [1971]. As a conceptual axis we found basis on the color studies from Wassily Kandinsky, on the light concepts of Denis Bablet and on the poetic traces written by Oiticica. Starting from the iconographic documents, considering the aesthetics interlocution between artists from the tropicalist moment, we aim to clarify how sound, light and scenography materiality could activate the image in direction to a living participation on the scenic environment.

Keywords: Hélio Oiticica; light-color; environmental scenography 
Usamos luz como se usássemos palavras, para elucidar ideias e emoções. A luz torna-se um instrumento, um meio de expressão, como o pincel de um pintor, o cinzel do escultor ou uma frase musical.

(Robert Edmond Jones, 1968, p.326)

A importante constatação acima do cenógrafo norte-americano Robert Edmond Jones (1887-1954), no início do século XX, parece elucidar o principal desafio que o advento da iluminação cênica adquire na encenação. Fornecer uma alternativa formal às metodologias tradicionais de concepção de um espetáculo teatral, conferir outras possibilidades espaciais a uma concepção cênica, revelar diferentes cores, siIhuetas, sombras e atmosferas para traduzir uma sensibilidade, atribuir novas temporalidades à cena e a uma dramaturgia, revelar a materialidade e tridimensionalidade da cenografia, dentre outros, todos estes, são artifícios que a iluminação desvelou para tornar a imagem cênica ainda mais ativa. Ora atrelada às noções da escultura, aguçando ou suprimindo a tridimensionalidade das estruturas sobre o palco; ora atrelada à pintura, atribuindo novas cores à materialidade e corpos em palco, a vivência da luz sobre o palco de um teatro de fato se relaciona com diferentes linguagens e pode suscitar importantes reflexões sensoriais quando analisada de forma cuidadosa.

É nesse sentido que se torna relevante investigar o percurso poético que o artista carioca Hélio Oiticica (1937-1980) traçou ao criar a ambientação cênica baseada na criação das áreas de cor para o show Gilberto Gil in Concert, realizado na St. Clement's Church, Nova lorque [1971]. Ao analisar a metodologia de criação de Oiticica para este show é possível perceber não apenas a maneira como a iluminação cênica atinge este ou aquele efeito na encenação, mas antes, perceber como a experiência da cor-luz se tornou um elemento intrínseco na poética de Oiticica para a busca de uma materialidade que estimula a vivência do sujeito na obra.

Os incontáveis estudos sobre Oiticica no contexto das artes visuais pouco sinalizam a importância que as artes cênicas adquirem na construção de sua poética. Entretanto, uma breve análise em seus estudos preliminares sobre a cor no espaço e o sentido de construtividade é suficiente para perceber que mais que identificar sua atividade artística a um meio expressivo, Oiticica estava interessado em criar estruturas que instiguem no sujeito a experiência estética. Se observarmos ainda de forma mais cuidadosa, perceberemos que o artista visava criar meios que proporcionem no sujeito a potência inventiva, criadora e propositiva. Oiticica cria, portanto, categorias conceituais como crelazer (ideia de lazer livre e criativo - PLAY) e mundo-abrigo para conduzir seus trabalhos à relatividade da ação performativa do sujeito no mundo, entendendo que a experiência estética não está dissociada do aspecto vivencial individual e coletivo. A busca por estruturas, ambientações e práticas que potencializem o aspecto vivencial da arte se tornou um eixo chave de sua trajetória artística. Nesse sentido, por ter iniciado sua trajetória artística na pintura o aspecto vivencial da cor tornou-se o primeiro mote investigativo. Inspirado nos estudos de Ernest Cassirer (1874-1945) e de Wassily Kandinsky (1866-1944), Oiticica estava convencido de que cor e a forma deveriam falar por si mesmas e se tornar "materiais" dos artistas. A cor não é simples atributo das coisas, mas é, sobretudo, estrutura e, por isso, possui um 
caráter vivencial. Na obra do artista brasileiro, cor e estrutura são elementos inseparáveis assim como tempo e espaço. Esses quatro elementos - cor, estrutura, tempo e espaço - são, para Oiticica, dimensões de um único fenômeno. A cor aparece, portanto, como um problema a ser investigado no que tange a ativação do corpo do sujeito no mundo. Nos primeiros Penetráveis (1960) o espectador é colocado no interior da cor. A cor-luz (branco, amarelo, laranja, vermelho-luz) foi investigada no primeiro momento somente na relação pigmento-estrutura. No entanto, conforme perceberemos a seguir este canal ganha novos contornos na poética de Oiticica conforme o artista se relaciona com outros eixos expressivos da cultura. A constante atenção aos estados inventivos dos sujeitos determinou um traçado antropológico na atividade artística de Oiticica. $O$ artista carioca investigava esses fenômenos valendo-se de sua intensa produção escrita e, por vezes, lançando seu corpo ao caráter experimental dessas vivências. De forma não hierárquica, a poesia concreta, o cinema underground, os happenings e sonoridades John Cage (1912-1992), música (tropicalista e o rock), o jogo de bilhar e o jogo de futebol no Maracanã, a dança dos passistas da Mangueira, os shows de rock ao ar livre, o teatro experimental, entre outros, tornaram-se percursos possíveis e fundamentais para "decantar estados de invenção", para suscitar estímulo corpóreo, sensorial e cognitivo do sujeito que se ativa por meio da obra. Para Oiticica, a possibilidade de o espectador girar $180^{\circ} \mathrm{em}$ relação à obra torna possível a passagem do campo da representação ao espaço real. O problema do tempo e do comportamento passava a ser um item explorado desde o início da criação artística. A busca por uma arte ambiental não reconhecia os limites impostos pela linguagem.

No livro The history and theory of Environmental Scenography (1981), Arnold Aronson analisa que, na direção contrária de muitas produções ambientais dos anos vinte e trinta ${ }^{2}$, a ideia de John Cage era de produzir um tipo de arte que fomentasse a percepção do mundo pelo "ouvir e ver" de elementos do próprio cotidiano. "Os elementos específicos perceptíveis em uma peça de Cage deveria ser diferente de tudo que é possível encontrar no mundo cotidiano, mas a sua percepção deveria ser a mesma"3 (Aronson, 1981, p.159-160) Para Cage, esse conceito de percepção do "em torno" era tão importante quanto a própria música. O compositor explicava que a música eletrônica, por exemplo, teria a capacidade de preencher a sala de espetáculos com apenas alguns amplificadores. Aronson ressalta que, naquele mesmo período, seguiam esta mesma direção os fundadores do Living Theatre, Julian Beck (1925-1985) e Judith Malina (1926-2015) para quem tanto o som quanto os recursos visuais estariam tomando espaço, "popping up". A proposta de Paradise Now, por exemplo, estendia as questões sociais às relações entre os problemas arquiteturais e eletrônicos. "Assim é como o teatro será... assim como os sons podem se mover ou parecem surgir de qualquer ponto no espaço... eu também gostaria que isso aparecesse, como eu penso que vai com meios transitórios, no centro do espaço"4 (Malina \& Back, apud Aronson, 1981, p.159). O som ajuda, portanto, a reestruturar as matrizes

\footnotetext{
${ }^{2}$ Nesse período as encenações estariam mais interessadas em intensificar os efeitos da interpretação

3 "The specific elements one perceived in a Cage piece might be unlike anything encountered in the everyday world, but the perception of them would be the same". (Tradução nossa)

4 "That's how theatre will be... so that sounds can move or appear to come from any point in space... I would also like it to appear, as I think it will with transistor means, in the center of the space". (Tradução nossa)
} 
da compreensão espacial, esta compreensão arquitetural apresenta novas relações entre o espetáculo e o público, o que estimula a intervenção do sujeito à cena e por consequência do mundo ao seu redor.

Vale lembrar que tanto o experimentalismo musical de Cage, quanto as práticas de teatro experimental do Living Theatre eram declaradamente fontes das principais referências de Oiticica sobre a atividade performativa. Não é de estranhar que os trabalhos de ambiente cênico para show de Gilberto Gil lidassem com questões que transpassam as investigações desses grupos. Durante a introdução da tradução - De segunda a um ano (2013) de John Cage, Augusto de Campos diz que o livro, escrito pelo norte-americano originalmente em 1963, se trata de um mosaico de ideias que, a partir da música, revela um experimentalismo linguístico. Para o poeta brasileiro, Rogério Duprat (1932-2006) foi um primeiro artista no Brasil a arriscar, no princípio dos anos 1970, a traduzir para o português um livro de John Cage. Segundo Campos, o compositor, arranjador e maestro brasileiro era responsável por "injetar o caos ao experimentalismo musical do momento tropicalista". Esse aspecto experimental do momento tropicalista sinalizava uma potência ativa no sujeito que fascinava Oiticica desde $1967^{5}$. A aliança circunstancial com os músicos considerados tropicalistas funcionou como uma tática de expansão de suas ideias, atingindo a atmosfera desejável da 'superantropofagia' que pretendia revisar o conceito de antropofagia resgatado por Oswald de Andrade (1890-1954) e estende-lo de maneira ainda mais radical aos eixos da cultura oficial e não-oficial por meio de uma atitude comportamental de qualidades anárquicas.

Desde 1969, quando voltou ao Brasil entusiasmado depois de sua permanência de um ano na Inglaterra ${ }^{6}$, Oiticica percebeu que fazer cenografia poderia ser uma maneira de inventar novas relações com o público sem qualquer precedente. $O$ desejo de ampliar a prática artística na direção do music-hall era menos uma estratégia das produções de show e mais uma tentativa do próprio Oiticica de estender suas ideias a outros meios como um exercício de linguagem. Além da inserção da bandeira "Seja Marginal Seja herói" no show de Caetano Veloso, Gilberto Gil e os Mutantes na Boite Sucata em 1968 durante a final do Festival Internacional da Canção, Oiticica criou em 1969 o projeto para a cenografia de um filme não-realizado chamado $A$ Cangaceira Eletrônica e a ambientação cênica para o show de Gal Costa também na Boite Sucata. A proposta de fazer cenografia também se apresentava como uma alternativa para obter certo retorno financeiro. Desde a criação dos Bólides na primeira metade dos anos sessenta, Oiticica se recusava a fazer uma "arte vendável" para preencher galerias ou estantes de colecionadores. Apesar de ter passado por algumas situações de dificuldade financeira, Oiticica só cogitava vender os trabalhos das fases iniciais - desenhos e metaesquemas - e em nenhuma hipótese aqueles que

\footnotetext{
${ }^{5}$ Foi por meio da repercussão da obra Tropicália [1967] de Hélio Oiticica durante a Exposição Nova Objetividade Geral no Museu de Arte Moderna do Rio de Janeiro que Caetano Veloso batizou o famoso disco Tropicália ou Panis et Circensis. [1967]. Foi também neste ano que estreou o filme Terra em Transe de Glauber Rocha e o espetáculo $O$ Rei da Vela do Grupo de Teatro Oficina que sinalizavam uma via alternativa que visava repensar a imagem-Brasil. 0 disco culminava a efervescência cultural do período e deu voz a diversas práticas artísticas de vários eixos da cultura brasileira. 0 momento tropicalista ganhou por meio da crítica musical o termo "tropicalismo" para definição de um grupo, apesar disso, muitos artistas recusaram o sufixo "ismo" alegando que não se tratava de um movimento organizado tal qual muitos movimentos modernistas, mas era uma postura comportamental que visava uma síntese de estrutura heterogênea. (Cf. Basualdo, 2007)

${ }^{6}$ Vale lembrar que que durante esse período, Oiticica realizou diferentes obras e homenagem aos músicos tropicalistas, tal qual Tenda Gil-Caetano e alguns Parangolés.
} 
se situavam no cerne do Programa Ambiental [Penetráveis, Parangolés, Bólides, etc.]. Dessa maneira, oferecer um serviço de cenografia ambiental para artistas renomados era uma tática de se manter financeiramente e, sobretudo, um meio de possibilitar a desejada expansão estética vivencial. Por outro lado, em 1969, principalmente depois da prisão e exílio de Caetano Veloso e Gilberto Gil, muitos artistas ficaram sem um rumo definido no Brasil, sem entender exatamente como se relacionar com o "calar" à euforia dos anos precedentes. Para Oiticica, estender as possibilidades de criação artística para o eixo da ambientação cênica era ainda uma forma de agitar e retomar não apenas o cenário cultural da música popular brasileira, como unir forças para encarar a nova face-Brasil sem medo. É nesse sentido que os principais trabalhos de cenografia, junto com as experiências cinematográficas, passaram a ser uma possibilidade concreta de atuação no retorno ao Brasil em 1970. Apesar da intensa dedicação de Oiticica nessa direção, o artista desviou este percurso quando se viu diante da oportunidade de expor e posteriormente de mudar-se para Nova lorque. A possibilidade de fazer uma cenografia para Gilberto Gil já no final de 1971 retomava a oportunidade para pôr em prática este caminho na cenografia. A direção para o eixo das artes cênicas (teatro, cinema e shows) encontrou nesta viagem de Nova lorque novos contornos por meio de seus trabalhos mais recentes. Vale lembrar que esse projeto de show foi realizado na sequência de seus planos para os complexos de penetráveis Subterranean Tropicalian Project ${ }^{7}$ e em paralelo ao projeto de Rhodeslândia (1971). O ambiente performativo realizado para um projeto na Universidade Rohde Island consistia em áreas livres de brita subdivididas por telas de nylon sob a inserção de uma iluminação artificial alaranjada. O desejo de Oiticica era que, tanto atores do Living Theatre, quanto alunos de artes da universidade, ocupassem as áreas livres como se elas fossem células de expressão nas quais pudessam germinar atividades vivenciais criadoras - não catárticas. Uma rápida análise das duas obras [o show de Gil e Rhodislandia] seria suficiente para percebermos a inter-relação existente entre os ambientes e notarmos que o caráter ambiental e performativo são alicerces para a escolha de planejar áreas livres de expressão com alguns dispositivos materiais que alimentem essas atividades, sejam eles estímulos sonoros, iluminação diferenciada, projeção de imagens dentre outros.

\section{Tropicalistas em Nova lorque}

Sobretudo no primeiro ano de sua morada novaiorquina ${ }^{8}$, Oiticica desfrutou de forte inspiração criativa. Planejou em maquetes o Subterranean Tropicalian Project, frequentou aulas de vídeo grego e latim, montou o seu Loft4-Babylonest (a peculiar casa-instalação onde morava), visitou constantemente as bibliotecas públicas, participou de inúmeras aberturas de exposições, vivenciou o contexto marginal da cidade, aventurou-se por práticas no cinema experimental underground, frequentou

\footnotetext{
${ }^{7}$ Estes são projetos de ambientes performativos para o espaço externo inspirados na obra Tropicália. Estes ambientes, além de configurar nova categoria espacial para suas obras pretendiam discutir o aspecto subterrâneo - underground - da vivência coletiva. Tomavam como prerrogativa a vivência-PLAY nos shows ao ar livre de grandes festivais de música tais quais Woodstock Music \& Art Fair e Isle Wright Festival. Em vida, Oiticica não pode ver esses trabalhos realizados em escala real, debruçou-se apenas nos seus projetos por meio de maquetes e detalhados relatórios técnicos dessas obras.

${ }^{8}$ Motivado pela participação da exposição Informations entre julho e setembro de 1970 no Museum of Modern Arts de Nova lorque, em dezembro de 1970 Oiticica retornou à cidade quando ganhou uma bolsa da Fundação Guggenheim.
} 
shows no Central Park, recebeu inúmeras visitas dos amigos brasileiros, realizou os seus delírios ambulatóriums, testemunhou experiências do teatro de vanguarda, escreveu textos crítico-conceituais em cartas e em artigos autorais em publicação no Brasil e, finalmente, frequentou inúmeras festas e reuniões com artistas de vanguarda. É, portanto, justificável o entusiasmo de Oiticica quando recebeu o convite para criar a cenografia-ambiental para o show de Gilberto Gil.

Além de estar na companhia de dois amigos, Gilberto Gil e Guilherme Araújo, a experiência lhe serviria para abrir mais uma frente de trabalho em Nova lorque ao mesmo tempo que possibilitava a prática de um ambiente performativo, dando curso, assim, a suas intenções iniciadas dois anos antes, em Londres quando criou os primeiros Ninhos (1969). O entusiasmo de Oiticica sobre o projeto crescia conforme identificava desdobramentos de trabalhos a partir deste show. Em uma carta de 25 de setembro de 1971 para o editor Luiz Carlos Maciel (1971, Tombo: 0904.71-p1.), prometeu-lhe um artigo para ser publicado no primeiro volume do jornal $A$ Flor do Mal. A reportagem sobre a produção artística de Gil - e dele, Oiticica - no exterior era um meio de manter-se aceso nos ciclos culturais que ainda sobreviviam no Brasil nos tempos de $\mathrm{Al}-5$.

Como aconteceu com diversos artistas brasileiros exilados durante ditadura militar, o período de afastamento de Gilberto Gil e Caetano Veloso em Londres serviu também de gatilho para a internacionalização de suas músicas. Tanto no depoimento de Joanne Pottlitzer ${ }^{9}$ quanto na biografia de Gilberto Gil escrita por Regina Zappa (2013), Gilberto Gil confirma que foi por sugestão de Augusto Boal ${ }^{10}$ que o Latin American Theater - St. Clement's Church chegou ao nome de Gilberto Gil. A ideia de fazer um show numa igreja-teatro off-Broadway em Nova lorque ia ao encontro dos interesses de Guilherme Araújo - o principal produtor musical do momento tropicalista - de lançar Gilberto Gil internacionalmente aproveitando o momento do exílio. Sua visita foi preparada para apenas cinco dias de apresentação, mas foi prorrogada de 5 a 17 de outubro. Na reportagem da Revista Manchete de 23 de outubro de 1971, o jornalista Lucas Mendes ressalta que o próprio pastor da St. Clement's Church fez o convite para que Gil cantasse também no culto de domingo (Mendes, 1971, p.111). A produção não possuía grandes recursos financeiros e este fator condicionou as características do show. Porém, por sugestão do produtor brasileiro, foi reservado um montante para as despesas de cenografia, sobretudo por aproveitar a coincidência de Oiticica estar em Nova lorque no mesmo período. Apesar do baixo cachê, o artista não considerava recusar a oportunidade, uma vez que poderia lhe abrir portas para o trabalho na área de shows e teatro.

Para Oiticica, tanto participar deste evento quanto relatar a projeção internacional de artistas exilados era de fato um posicionamento político, dizia respeito a um estímulo criativo que visava divulgar a resistência de uma postura de contracultura e experimental. $O$ artista planejava fazer fotografias de Gilberto Gil e desejava a participação do cantor em seus projetos experimentais cinematográficos.

\footnotetext{
${ }^{9}$ No St. Clement's Church - Latin American Theater, Joanne Pottlizer, foi a pessoa que coordenou a produção em Nova lorque. Além do show, durante a estada em Nova lorque, Guilherme Araújo também negociou junto a Pottlitzer a divulgação do show pela rádio local e uma aparição de Gilberto Gil num programa chamado Camera3 na emissora de TV CBS.

${ }^{10}$ Oiticica chegou a trabalhar no mesmo teatro com Augusto Boal durante a montagem da Feira Latino Americana de Teatro em 1972.
} 
Na ocasião, a dupla Gilberto Gil e Guilherme Araújo tentava repetir o plano de ação realizado no show da Gal Costa na Boite Sucata no ano anterior ${ }^{11}$. Oiticica seria o responsável tanto pela cenografia assim como pela programação visual do álbum que sucederia o show. Do final de outubro até novembro de 1971 Oiticica se ocupou em fazer o layout da capa. Em carta o artista explicava:

[...] eu hoje bolei todo o layout da capa do disco novo que Gil vai gravar em Londres: se aceitarem e sair tudo normal, o que estou certo, vai ser a melhor capa que ele já teve; as fotos (ou foto, dependendo de se vai ser álbum ou não; fiz 2 layouts, para álbum e para disco simples) são de Miguel Rio Branco, são lindíssimas; adorei fazer esse trabalho, em meio a outras coisas. [...]; de modo que lá pro dia 28, Guilherme recebe o layout; sinto-me mais aliviado em ter terminado isso. (Oiticica, 1971, tombo 0846.71- P.1)

Os planos de lançar o álbum de Gil pela Paramount ${ }^{12}$ acabaram quando os brasileiros decidiram retornar para Londres por houver a possibilidade concreta de retorno dos artistas exilados para o Brasil em dezembro de 1971/janeiro de 1972.

Apesar disso, na biografia autorizada de Gilberto Gil é possível perceber a importância que o cantor dedicou a este encontro em sua carreira. Assim como podemos analisar nas cartas de Oiticica e nas reportagens da época, Regina Zappa menciona que Gil foi ao encontro de João Gilberto ${ }^{13}$, que morava em Nova lorque na época, perambulou nas ruas do Harlem com os amigos, ficou hospedado na casa de Oiticica e frequentou inúmeras festas dadas por artistas após cada dia de espetáculo. "Foi um período incrível. Foi quando me estabeleci definitivamente como músico no circuito mundial. Foi fundamental, cheio de cores, amenas ou mais densas. Um período muito rico" (Gilberto Gil apud Zappa, 2013, versão digital Kindle).

A imprensa brasileira da época confirmava que o principal interesse de Gil era de cuidadosamente abrir caminho de seu trabalho no contexto nova-iorquino. Na referida reportagem da Revista Manchete o jornalista destaca que a tranquilidade com a qual Gil comentava sua projeção internacional era incomum aos artistas brasileiros. Segundo a reportagem, cuidar da aparência e saúde, se estabelecer no contexto musical internacional e curtir a vivência da noite norte-americana junto aos amigos eram os principais objetivos do cantor. Guilherme Araújo estendia suas funções de produtor ao cuidado com a sua aparência pessoal sugerindo, por exemplo, que Gil não se apresentasse de sapatos no show, preferindo as sandálias. O modo integrado ao contexto nova-iorquino - que ainda era violento e subversivo e sofria as consequências da sangrenta luta contra a segregação racial da década anterior - tornou Gilberto Gil, um cantor negro latino-americano, um ícone importante para aqueles que o conheciam. Jorge Mautner, que também estava em Nova lorque na ocasião, relatou ao jornal O Pasquim novembro de 1971 a simplicidade com a qual Gilberto Gil cantava e tocava violão no Washington Square Park ao lado de "crianças de cabelos compridos como anjos brincando ao redor, muitas folhas no chão de outono,

\footnotetext{
${ }^{11}$ Oiticica assinou a capa do disco LeGal e a ambientação cênica do show de Gal Costa que aconteceu no Rio de Janeiro na Boite Sucata em 1970

${ }_{12}$ Produtora norte-americana.

${ }^{13}$ Seu principal ídolo brasileiro
} 
um porto-riquenho e um preto do Harlem com cabelo afro dançando ao som de Gil" (Mautner, 1971). Era dessa maneira que Oiticica gostaria de apresentá-lo ao contexto americano "quero fazer uma coisa alegre, mais para o contagiante, para não dar impressão de 'um artista sério do Brasil'"' (Oiticica, 1971, Tombo: 0904.71-p1.)

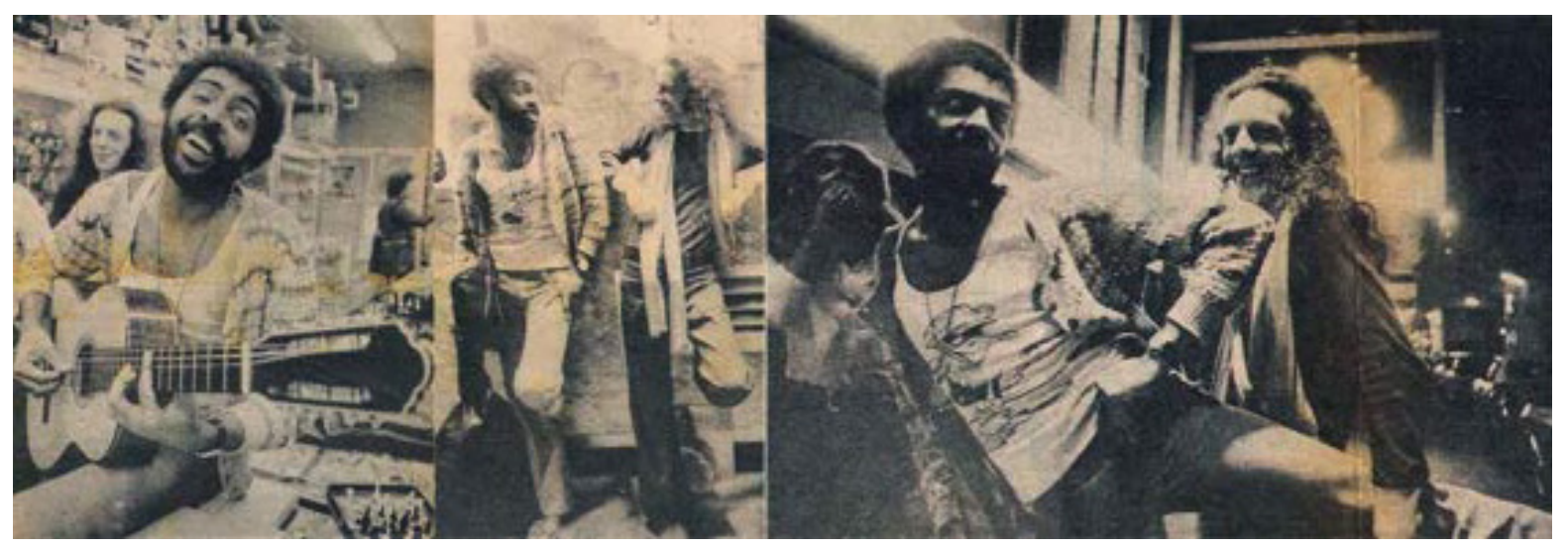

Fotografias de Gilberto Gil e Hélio Oiticica nas ruas de Manhattan (Halem e Village) publicadas no Jornal o Pasquim.

Foto: Carlos Vergara Arquivo: H.O. Tombo: 0884.71 


\section{Gilberto Gil in Concert}

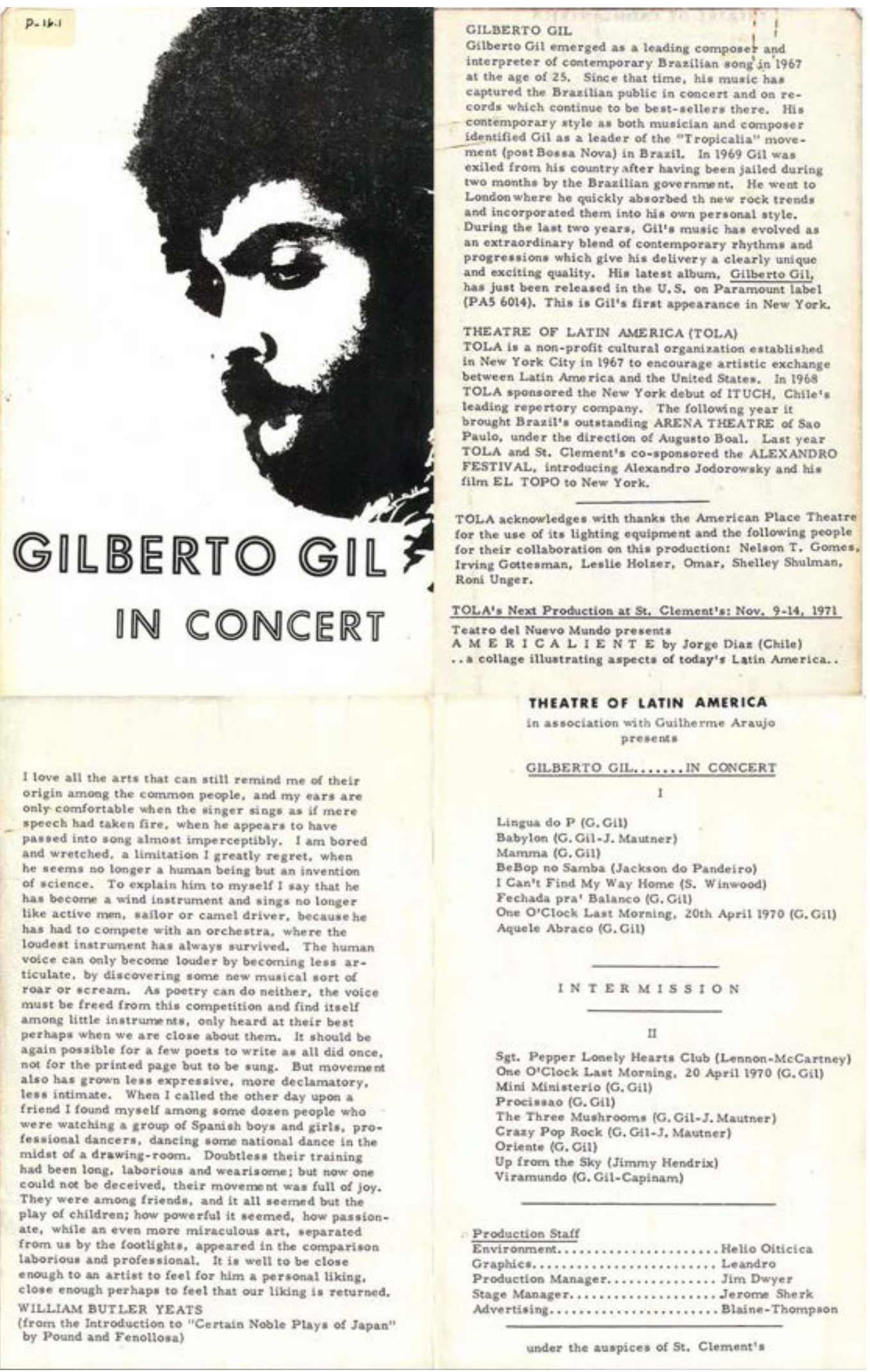

Programa do Show Gilberto Gil in Concert realizado em outubro de 1971.

Arquivo: H.O. Tombo: 2367.71 
O trecho do livro The Classic Noh Theatre of Japan de Ezra Pound e Ernest Fenollosa (1959) indicava a atmosfera desejada no show. O texto escrito por William Butler Yeats foi escolhido por Oiticica para integrar o programa do espetáculo. Yeates ressalta que para ser poeta - ou cantor - é necessário estar livre de competições, é necessário coordenar os sons e as vozes àquilo que se deseja dizer e que, nem sempre, é dito por meio de palavras. O fragmento sugere a importância de reconhecermos no artista as qualidades de um ser humano e não de uma invenção científica. $O$ desejo de Yeats era de que a arte criasse um ambiente entre amigos, como se fosse uma brincadeira de criança, e não separados por uma ribalta para dar a impressão de muito trabalho e profissionalismo. Oiticica explicava para Haroldo de Campos que escolheu este fragmento porque percebeu no trecho "algo de repúdio aos 'cantores discursivos', que ali seriam os de ópera, mas que na realidade conhecemos outros, os de música popular" (Oiticica, 1971, Tombo: 0859.71). A advertência de Oiticica era para a rejeição maciça no Brasil às músicas como Questão de Ordem e Batmacumba durante os festivais de 1968. Para Oiticica o que o poeta irlandês questionava, poderia ser aplicado "à rejeição do discursivo comum a um GIL, HENDRIX, NÔ, etc." (Oiticica, 1971, Tombo: 0216.71). ${ }^{14}$

Eu amo os trabalhos artísticos que ainda me lembram suas origens entre as pesso-
as comuns, meus ouvidos apenas ficam confortáveis quando o cantor canta como
se um mero depoimento tivesse incendiado, quando ele aparenta ter passado por
meio de uma música quase imperceptível. Eu fico entediado e infeliz, uma limita-
ção que realmente lamento, quando o cantor não parece mais que um ser humano
mais uma invenção da ciência. [...] É bom estar perto o suficiente de um artista
para senti-lo como uma preferência pessoal, perto o suficiente para sentir que a
nossa preferência foi retribuída. ${ }^{15}$ (Yeats. In: Programa Show Gilberto Gil in Con-
cert, 1971, Tombo: 2367.71)

Trabalhar no show de Gilberto Gil era colocar em prática suas leituras, suas ideias, sua aprendizagem no mesmo momento em que elas estavam sendo construídas. As palavras de Yeats se relacionavam ainda com o entusiasmo pessoal de Oiticica ao estar diante dessa oportunidade de trabalho. O texto indica, sobretudo, a forma reflexiva com a qual Oiticica se relacionava com um dos cantores que mais admirava na música brasileira. "[...] a presença física de Gil é o que a música é: essencial" (Oiticica, 1969, In: Figueiredo, 1998, p. 133). O fascínio por Gilberto Gil crescia conforme se percebiam partilhando as mesmas referências.

Nesse projeto, a mútua admiração por Jimi Hendrix ressaltava. Gal Costa confirmava a influência: "Naquela época [1967-1970] [eu] convivia com todo o ambiente tropicalista. Só falávamos dos movimentos novos que surgiam no mundo. Gil ouvia Hendrix o dia inteiro" (Costa, 2005). O cantor norte-americano havia morrido no ano anterior, em 18 de setembro de 1970, e era um dos principais norteadores rumo ao discurso de liberdade comportamental atrelado ao teste dos limites de sua linguagem poética. O show se tornou uma espécie de tributo ao guitarrista. Uma home-

\footnotetext{
${ }^{14}$ Vale lembrar que tanto Jimi Hendrix [1942-1970], quanto o Teatro Nô japonês são referências recorrentes nos escritos de Oiticica.

${ }^{15}$ I love all the arts that can still remind me of their origin among the common people, and my ears are only comfortable when the singer sings as if mere speech had taken fire, when he appears to have passed into song almost imperceptibly. I am bored and wretched, a limitation I greatly regret, when he seems no longer a human being but an invention of science. [...] It is well to be close enough to an artist to feel for him a personal liking, close enough perhaps to feel that our liking is returned. (Tradução nossa)
} 
nagem que curiosamente prescindia de instrumentos elétricos a não ser pela própria voz amplificada pelos microfones. Na crítica que escreveu para o lançamento do Jornal Flor do Mal, Oiticica fez uma comparação cuidadosa que associava a prática de "cuspir sílabas rápidas sintéticas" realizada por Gil com o "contato elétrico" nas performances de Jimi Hendrix acompanhado por suas guitarras. Oiticica explicava que o show "é um cantar não-discursivo como se a palavra se eletrificasse". (Oiticica, 1971, Tombo: 0216.71-p1) Este elemento "não-discursivo" se transforma, portanto, em matéria sonora que ganha corpo por meio de palavras, da instancia performativa e da experiência sensorial do ambiente cênico. Em carta para Haroldo de Campos, Oiticica descreve:

Gil no show, só, com violão acústico, evoca Hendrix cantando 'Up from the skies' , bem diferente da evocação da gloriosa 'Questão de ordem' (festival-mutantes, etc.) mas ambas se encontram nesse ponto: não-discursivas; nessa de agora gil procura dizer as palavras como se cuspisse, como Hendrix, parodiando-o, e, ao contrário de Hentrix, com o uso de um simples violão acústico: a incorporação qualitativa dada pela guitarra-cantar elétricos, aparece agora com o violão (de um modo limitado, é claro), o que mostra ser mais inaceitável agora, cantor discursivo tipo Vandré, etc.; outra coisa de que gosto muito, é quando Gil canta gageijando uma parte de crazy pop rock dele e Jorge Mautner, quando diz: 'when i talk $i$ cannot talk': a pausa magistral é dada entre o talk e o i : taaaaalk, longo; eletric man-eletric lady. (Oiticica, 1971, Tombo: 0859.71)

A natureza concretista da performance de Gil é ressaltada por Oiticica e complementa a pesquisa de Oiticica no período. É interessante perceber que, mesmo com profunda admiração pelos Beatles, por exemplo, o que mais chamava atenção para esses artistas neste conjunto partia de premissas distintas. Enquanto para Gilberto Gil o que ressaltava era a maneira não hierárquica e descompromissada de como os Beatles mesclavam valores da música erudita renascentista aos ritmos tradicionais de sua cultura popular, incluindo aí a música oriental (Gil. In: Campos, 1974, p. 192-193). Para Oiticica fascinava o modo como os Beatles libertavam os corpos "desajeitados" dos ingleses a partir da música indiana (Oiticica, 1973, Tombo: 0504.73). O exercício de liberdade e sentido de descompromisso dos criadores de Eleanor Rigby e Sgt. Pepper's Lonely Hearts Club Band, músicas que integravam o repertório do show, resultavam na composição de Oriente e no ambiente-jardim idealizado para o show.

Gil canta no show uma música nova de incrível beleza e sugestão de viagem para o Oriente onde está a magia e o desconhecido. Num trecho ele diz: "Considere rapaz, a possibilidade de ir pro Japão, num cargueiro do Lóide lavando o porão...". E a impressão é de que Gil já foi a este oriente, ou que está indo num cargueiro do Lóide, lavando o porão, tocando violão, tirando um som, tanto faz, de qualquer maneira ele já foi, está indo e irá cada vez mais para o oriente, para este Oriente do Oriente que Fernando Pessoa falava, e que é moradia da imaginação, do delírio da grande noite cósmica daonde ele retorna com ciscos de estrelas, da fantasia, soberana como a loucura, onde todos os êxtases vão além das fronteiras, onde a beleza é sempre reencontrada sob forma diferente. (Mautner, 1971)

Foi acompanhando esta atmosfera de admiração e trocas que Oiticica desenvolveu a cenografia para o show. Para enquadrar-se no orçamento limitado, Oiticica planejava: "vou fazer algo bem simples, baseado em áreas de luz e cor" (Oiticica, 1971, Tombo: 0906.71). A igreja-teatro transformava-se "num lugar mágico criado 
por Hélio Oiticica que usou todo seu poder de feiticeiro para criar um ambiente infernal" (Mautner, 1971). Ainda assim, conforme a produção acontecia a negociação financeira se tornava um obstáculo frequente ainda mais severo que as produções realizadas no Brasil:

[...] [Joanne está] achando que estou gastando milhões apesar de brita custar 3 dólares [...] e o mylar, 8 yards, 16 dolares; claro que vou fechar os dois lados com tela de nylon (como as dos ninhos) pra ficar mais enclosed; [...]. (Oiticica, 1971, Tombo: 0759.71-p2)

Na arquitetura da St. Clement's Church, Oiticica criou um ambiente que desdobrava o seu trabalho Ninho (1969) e abrigava toda a sala de espetáculo. A sala multiuso, de aproximadamente $23 \mathrm{~m} \times 12 \mathrm{~m}$, era limitada tanto pelas paredes da igreja-teatro em dois lados quanto por duas grandes telas de nylon nos outros lados. Uma das telas foi posta onde o público entrava e outra na extremidade oposta por onde Gilberto Gil entrava. Toda a área cênica e o público ficavam entre estes dois "véus naylonizados". A escolha pela tela de nylon era recorrente nos trabalhos de Oiticica no período e agiam como um filtro cinematográfico à área cênica. Deseja-se um filtro, uma outra perspectiva sobre a arquitetura cênica. Anular a exterioridade da obra, impossibilitar sua visibilidade, seria ignorar sua existência e a obra de Oiticica, ao contrário, deseja estabelecer uma atmosfera, um ambiente que dialogue com o real e não criar um simulacro ilusionista. O filtro-nylon delimitava a área aberta à performance que não se isolava ao ambiente cotidiano, mas tornava difusa a percepção sensível entre a realidade e ficção. Entrar no teatro era como entrar num ambiente-ninho. Ali dentro do Ninho-teatro seria possível criar uma atmosfera livre e performativa, uma área aberta à invenção, à participação no ambiente abrigo.

No interior do ambiente-ninho, os espectadores eram dispostos em quatro arquibancadas em torno da área cênica. A distribuição dessas arquibancadas acompanhava a geometria quadrangular da estrutura central. Pelas críticas, seja em cartas ou em jornais da época, é possível perceber que Oiticica cuidou de uma alteração dramática conforme se apresentava a intensidade sonora na performance de Gil. Assim como o show era dividido em dois momentos, a estrutura era dividida em duas áreas. Em cada momento, por meio da iluminação e da disposição de Gilberto Gil no ambiente, cada uma dessas áreas ficava em evidencia.

Antes do intervalo a área que se destacava na cenografia deveria refletir tanto a iluminação quanto a própria imagem de Gilberto Gil. Oiticica criou um praticável e o revestiu com um material tipo plástico prateado (mylar). Sobre esse nível - o mais alto da cenografia-, o cantor tocava violão acústico sentado em um banco alto também revestido desse material prateado. Depois do intervalo, Gil usava este praticável metálico apenas como passagem. Duas rampas tornavam possível o acesso entre os ambientes. O cantor subia pela rampa que ia do nível da sala de espetáculos até o nível praticável e descia por outra rampa que ligava o praticável até a segunda área. Gilberto Gil se posicionava no banco que, agora, estava no canto oposto ao anterior, na nova área de atuação. Este ambiente era uma espécie de jardim japonês feito de pequenas pedras de obra. Nos Penetráveis de Oiticica, o ato de entrar no ambiente, retirar os sapatos e caminhar pela água, areia ou brita instigava o espectador e, nesse 
caso, as matérias escolhidas estimulavam Gilberto Gil a redescobrir suas sensações, redefinir suas sensibilidades e agir de forma singular. O corpo utópico (Foucault, 2013, p.14) do cantor se dilatava durante o espetáculo e revelava por meio das áreas cênicas uma espacialidade simultaneamente interior e exterior. Era necessário uma redescoberta do próprio corpo para que fosse possível ativar este ambiente.

[...] trata-se nesse caso de brincar-aprender sensações não só visuais como também táteis-corporais como se o PENETRÁVEL fora (e o é) um jardim-síntese para um ambiente fechado: não uma 'representação de jardim' mas um amálgama $^{16}$ jardim puramente inventado. (Oiticica, 1979, Tombo: 0102.79-711)

Vale lembrar que Foucault considera o jardim como um dos exemplos de "heterotopia" que mais persiste entre as civilizações justamente por coexistir duas características: a universalização e a felicidade. (Foucault, 1984) A área-jardim de pedras lembra a cama-bólide realizada para o complexo Éden (1969). Entretanto, ao invés de feno onde os participantes se deitam e gozam de sua atitude-lazer, a área recebia brita como matéria base de preenchimento. A brita sobre a madeira se tornava uma área play-sonora para o cantor. Das poucas coisas que a produtora Joanne Pottlitzer pode se lembrar sobre o show ${ }^{17}$, uma delas ainda a deixava emocionada enquanto relatava sobre a cenografia: os sons gerados pelo caminhar de Gil na área de brita. $\mathrm{A}$ ação simples de Gilberto Gil tornava a cenografia um potente instrumento de percussão. Como foi relatado, o cantor usava apenas a sua voz e um vilão acústico projetados por meio de dois microfones e dois amplificadores. A utilização do espaço pelo caminhar, pela dança ou pelo "bater dos pés" de Gil parecia ganhar mais importância quando associada aos efeitos de iluminação criados por Oiticica. A superfície cinza, metalizada e reflexiva dos materiais escolhidos para compor as estruturas dava ainda mais potência ao ambiente de luz projetado pelo o artista. Assim como muitos trabalhos em artes cênicas no período, a iluminação adquiriu uma qualidade material da luz em seu próprio favor e de diferentes maneiras se tornou um item fundamental na criação da performance (Baugh, 2005, p.119).

Segundo Baugh (2005), durante o século XX categorias como cor, transformação, movimento foram exploradas pelos artistas do teatro como contribuições importantes da iluminação e cor atmosférica. Essas categorias implicaram em profundas alterações à metodologia e materialidade da cenografia. Atento às práticas de encenação no teatro experimental, Oiticica se alimentava das diferentes pesquisas no âmbito da luminosidade cênica. Por meio deste show, sob os feixes filtrados dos refletores associada à materialidade sonora da voz amplificada de Gilberto Gil e materialidade estrutural das pedras e do plástico reflexivo, o artista retomava o estudo sobre a cor-luz do início dos anos sessenta. Naquela época por meio do estudo sobre a cor-pigmento, Oiticica desejava atribuir-lhe o sentido de luz. Para ele, a cor-luz ativa uma certa qualidade temporal. $O$ artista considerava que a cor-luz volta à estrutura mesma para ativa-la, para revelar o próprio cerne puro e ativo, construindo a própria estrutura. Seu sentido é o inverso da abstração, mas revela uma característica de sín-

\footnotetext{
16 "Mistura de diversos elementos.

${ }^{17}$ Durante entrevista a Joanne Pottlitzer realizada em 11 de fevereiro de 2015 em Nova lorque.
} 
tese ativada pelas tonalidades que tornam a cor mais luminosa ou mais sombreada.

Em 1971, para realizar composição cênica por meio da iluminação, Oiticica também seccionou o ambiente em duas áreas. Uma diagonal separava as áreas acompanhando a divisão dos níveis da cenografia. Na primeira parte do show o ambiente metálico era completamente banhado em azul enquanto no outro lado da diagonal a cor vermelha prevalecia. A atmosfera celeste apaziguadora e profunda era ressaltada por meio do plástico mylar. Segundo Kandinsky (1993, p.92-93), a cor azul contém uma qualidade concêntrica do movimento, afastando-se do próprio homem. "O azul profundo atrai o homem para o infinito, desperta nele o desejo de pureza e uma sede sobrenatural" (Kandinsky, 1993, p. 92). Entendendo que a cor azul possui pouca atividade, Oiticica tencionava-a junto à composição com a iluminação vermelha. Revelando características de força, impetuosidade, energia, decisão, sedução, triunfo, paixão, os tons de vermelho ativam a área não utilizada por Gil neste momento do show. Oiticica considerava o vermelho-vivo uma cor-luz por excelência que estaria voltada para si mesma. A agitação da cor viva e ardente do vermelho revelaria características espaciais que elucidam sua própria energia e se contrapunha à impressão apaziguada da atmosfera celeste do azul. Para dar destaque ao músico situado na área azul, havia apenas um foco de luz branca no cantor. Não havia variação de iluminação até a última música deste ato: "AQUELE ABRAÇO, quando as áreas de cor vão desaparecendo e a imagem de GIL se silhueta até a escuridão e tudo reexplode e GIL sai: desce do praticável de chão de mylar (plástico que reflete espelhando), por uma rampa preta, e desaparece por trás dos véus nylonizados" (Oiticica, 1971, Tombo: 0216.71).

É importante destacar que os dez minutos de intervalo ganharam uma potência diferente com transposição temporal e atmosférica das áreas de cor. Era nesse momento que havia alteração gradativa das cores-luz do ambiente. O efeito transformava lentamente a atmosfera desejada para o segundo ato. O lado que era azul foi substituído pela cor vermelha e o lado da área de brita que, antes, era vermelha recebia agora a cor amarela. O resultado alaranjado da combinação amarelo-vermelho do segundo ato sinaliza certa vontade de expansão da atração do vermelho quente retornando-o em direção ao espectador. No laranja, o caráter corporal do vermelho acrescenta seriedade à alegria contínua do amarelo. Para Oiticica o laranja é uma cor mediana por excelência em relação ao espectro das cores. Entretanto, diferente do azul, não tende à profundidade, possui um caráter material ativo. Para Kandinsky (1993, p. 99) a composição alaranjada: “É como um homem seguro de sua força e que dá a impressão de saúde. Soa como um sino de ângelus, tem a força de uma poderosa voz de contralto". Não é de estranhar que a imagem de Gilberto Gil ganhe esta característica quando analisamos as críticas da época.

Foi na área mais amarela que Gilberto Gil se posicionava durante a maior parte do segundo ato. Kandinsky ${ }^{18}$ adverte que o amarelo atinge com facilidade os agudos e é a representação colorida da loucura e do delírio. Tal qual Kandinsky, Oiticica escrevia nos seus primeiros estudos sobre a cor que o amarelo, ao contrário do branco,

\footnotetext{
${ }^{18}$ Cristopher Baugh esclareceu que Kandinsky realizou experiências a respeito da música colorida ao escrever a peça The Yellow Sound em 1912. Sua investigação sobre a abstração coincidiu com a tentativa de pintores de perseguir a arte não-representativa. Esse estudo inspirou o experimentalismo dos ballés russos e futuristas do início do século XX. (Baugh, 2005, p.120)
} 
é uma cor menos estática e que possui forte pulsação ótica. Por ser uma cor que tende a se direcionar na direção de quem o olha, tem forte aspiração ao espaço real. Por vezes o amarelo se desprende da estrutura material e se expande no espaço. Esta cor possui características tipicamente terrestre e propõe uma desordem por excitar o homem. Para Oiticica, o amarelo era de suma importância para o sentido de luz temporal. Banhar Gilberto Gil nesta cor, era dar-lhe uma característica expansiva de forte atividade, por vezes esquizofrênicas. "ST. PEPPER'S LENNON-MACCARTNEY abre: a full-light se restringe ao amarelo-vermelho ambiental + o spot" (Oiticica, 1971. Tombo: 0216.71). Entretanto, diferente do primeiro momento do show, a cena se alterava nas duas últimas músicas. Oiticica retirava a cor-luz amarela durante a performance da música Up from the sky de Jimi Hendrix. Uma atmosfera "eletrônica e infernal", como descreve Jorge Mautner (1971), surgia da relação entre a evocação de Hendrix realizada pela voz de Gilberto Gil. Neste momento, o ambiente cênico ficava restrito entre o vermelho, foco branco sobre o plástico reflexivo e o lugar do cantor na área de brita, respectivamente. A sedução e o fogo do gozo estético no ato de Jimi Hendrix de queimar sua própria guitarra elétrica durante o Festival de Monterey em 1967 era agora transposto à luz atmosférica vermelha sobre o mylar e a voz de Gil durante este momento. A composição Viramundo encerrava o repertório com as luzes mais intensas (incluindo o amarelo) "GIL explode em VIRAMUNDO: as luzes se acendem como um sol sobre o quintal de brita" (Oiticica, 1971, Tombo: 0216.71-p2). Gilberto Gil ainda homenageava Oiticica quando dedicava a música Exaltação à Mangueira de Jamelão no bis.

Gil apresenta seu show regular mergulhado num ambiente onde luzes vermelhas, amarelas e roxas se acendem e apagam como sóis e estrelas de Galáxias desconhecidas. Às vezes o lugar parece um sítio pré-histórico, outras quando a luz fica branca e brilha em cima do cascalho parece que o lugar é uma praia bahiana cintilando fosforescências, quando Gil canta a canção de Jimi Hendrix o lugar fica eletrônico, quando Gil canta 'aquele abraço' o lugar irradia carnaval. (Mautner, 1971)

A opção por valorizar as áreas de luz era um indicativo relativamente novo no trabalho de Oiticica. A qualidade pictórica, sensorial e atmosférica da luz atribuía novos valores à imensidão que a investigação do artista desvelava ao considerar ambientações cênica constitutivas do repertório poético. É claro que a variação tonal pela luz pictórica - e deslocamento do espectador - no espaço já estava presente desde os Bilaterais, Relevos espaciais e Núcleos (1959-1961). A experiência temporal é revelada por meio da incidência da luz sobre a superfície monocromática no espaço. É justamente a conjugação entre o deslocamento do espectador e sua percepção acerca da variação tonal que a luz propicia quando incidida na superfície que determinará a consciência espacial, temporal e sua relação com a estrutura. Oiticica atenta o espectador que a luz determina nessas obras uma caraterística cinética e dinâmica à variação da estrutura monocromática. Pretende tornar o espaço físico pictórico determinante para a compreensão da estrutura. Entretanto, após esta ambientação para o show de Gil, em junho de 1972, Oiticica projetou um penetrável chamado Filtro (1972), no qual a cor-luz retoma a importância, pelo caminhar dos seus corredores. Como nas performances de John Cage, a ideia era de utilizar diversas mídias de 
forma sensorial a partir do conceito de jogo. O desejo era de "deglutir as imagens" de forma a desmistificar as estruturas ali expostas - labirinto-ruído-som-gravador-transistor-buzzer-liquidificador-tv - Oiticica projetou cortinas de plástico verde, azuis, amarelas e laranja que filtram a luz branca natural e artificial. Essas cortinas funcionam para o olho assim como as gelatinas agiam nos refletores da época. No final da experiência ainda eram oferecidos copos de sucos de laranja para que cada participante tivesse a sensação de estar bebendo a própria cor.

Por meio do artigo de Denis Bablet (1968) sabemos que nas experiências de teatro expressionista a iluminação colorida era um dos principais agentes para pontuações sensoriais e atmosféricos ao espetáculo. Para o teatro épico, por outro lado, o uso da cor agia como um potente recurso para alterar o estado natural dos elementos cênicos conferindo-lhes uma autenticidade circunstancial a fim de desorganizar a imagem cênica naturalista e inserir comentários à cena. Entretanto, o esbanjamento de feixes coloridos no teatro muitas vezes poderia ser questionável por criar múltiplos efeitos decorativos de grande habilidade técnica, mas de pouca substancia crítico-conceitual. A função dramatúrgica com a qual Oiticica propõe o desenho de luz para o show de Gil indica grande atenção a este possivel desvio. As poucas variações luminosas e a forma cuidadosa com a qual criou o projeto em relação ao programa do espetáculo sustentam esta prerrogativa. Além disso, a maneira com a qual Oiticica dispõe do discurso pictórico por meio da iluminação parece desejar revelar a cor e a matéria com máxima autenticidade, tal qual os efeitos épicos. A desejável interlocução entre a performance do ator e a sonoridade musical ganha com a iluminação uma característica singular a partir do apagamento do limite existente entre a área de encenação e o público. 
Hélio Oiticica e Gilberto Gil durante a montagem do Show

Gilberto Gil in Concert, St. Clement Church

Outubro de 1971, Nova lorque Foto: Não reconhecido Arquivo: H.O. Tombo: 2274.70-p1

how Gilberto Gil in Concert, St.

Clement Church,

Outubro de 1971, Nova lorque

Foto: Gerald Davis

Arquivo: Revista Manchete no 1018. Out de 1971, Rio de Janeiro

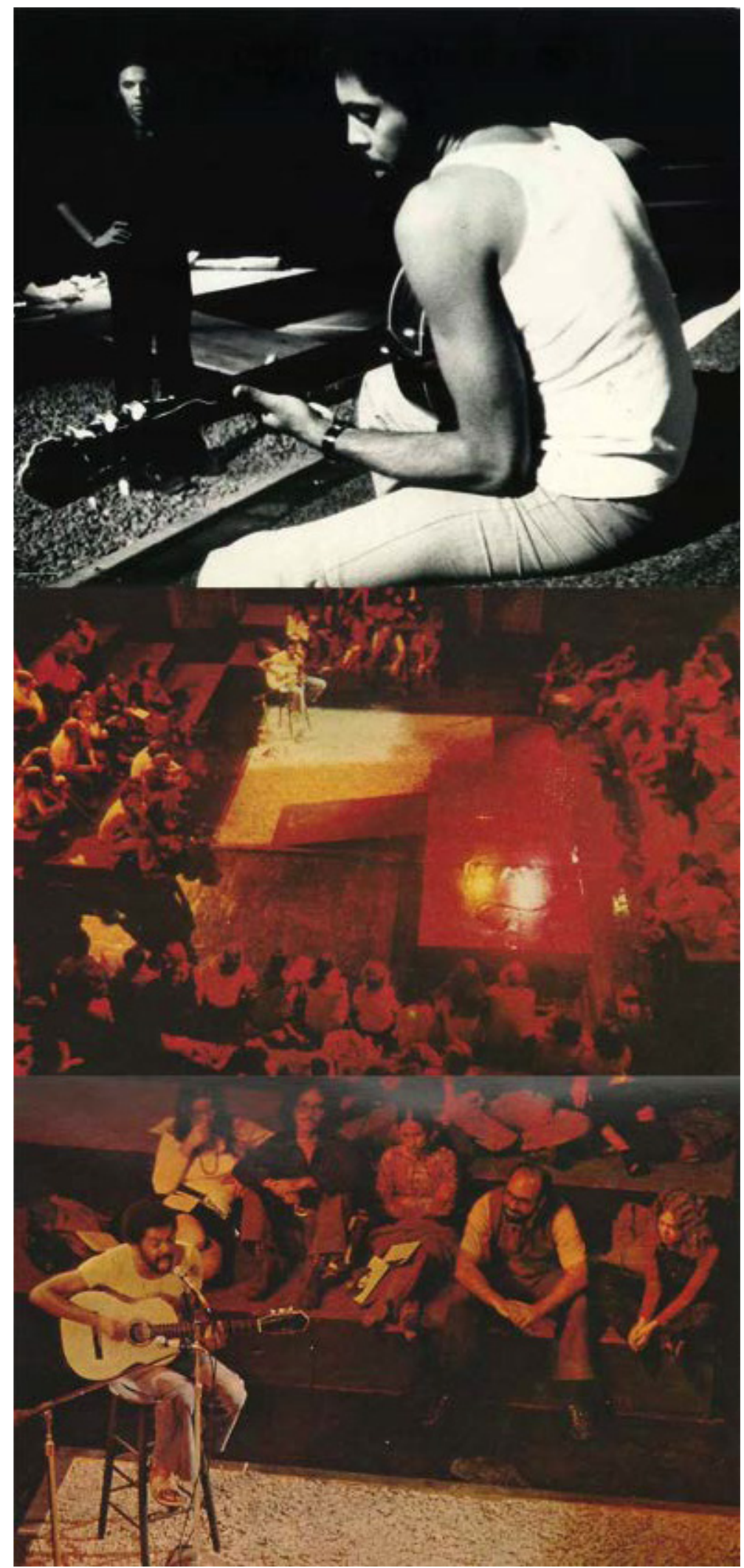

Aronson (1981) defende que a ideia de que um dos principais insights de Allan Kaprow é que o visitante de um Environment se torna um aspecto intrínseco deste ambiente. Para o pesquisador, esta característica direciona as formas teatrais que

19 "Peter Brook's idea [Empty Space] is to faintly refer to the space in the beginning, leaving the audience to build the rest in their imagination." (Tradução nossa) 
questionam o espaço antes de Kaprow para caminhos diferente àqueles tomados pelos Environments e Happenings. O distanciamento temporal e espacial e as matrizes cênicas (dramaturgias) criadas no teatro impossibilitariam a incorporação do espectador ao espetáculo mesmo que o público estivesse fisicamente dentro da cenografia ou que fossem convidados a participar da encenação. A única possibilidade de fazer o espectador coexistir ao ambiente é eliminar essas matrizes do processo de construção da cena. A cenografia ambiental deveria contribuir para um impacto sensorial que diminuísse o distanciamento entre ação performativa e a sensação presente. Podemos dizer que é nessa mesma perspectiva que o cenógrafo e arquiteto Jean Guy Lecat interpreta a maneira como Peter Brook entende por espaço vazio. Para o arquiteto, quando criada somente para o palco, a cenografia impede que o espectador compartilhe a experiência. "A ideia de Peter Brook [Espaço Vazio] é para francamente se referir ao espaço no começo, deixando o público construir o resto em sua imaginação"19 (Lecat, 2006).

A própria escolha pela disposição em arena, que recusa o distanciamento arquitetônico imposto pela frontalidade, era uma tática incomum a shows daquele período. Compartilhar o ambiente cênico e as reações que ressaltam dos outros espectadores já era compartilhar uma parte das vivências daquele show. Mas o desejo de que os espectadores compartilhassem a experiência fazia Oiticica pensar estratégias para integrar ainda mais os espectadores no mesmo recinto-ninho-penetrável. Para tal efeito, o artista planejava, inclusive, integrar pássaros no ambiente, tal fizera nos complexos ambientais dos anos anteriores, "pensei em colocar pássaros vivos, etc." (Oiticica, 1971. Tombo: 0759.71-p2). O que muitas vezes era uma tática de ressaltar a imagem-Brasil, aqui passava a formar um elo entre as experiências que daquele jardim surgiam.

Foi também nesse sentido que Oiticica se indignou quando houve retaliação por parte da produção a partir de um efeito de iluminação desejado. O artista idealizava que as áreas de luz abarcassem toda a extensão da plateia. "Adorei ter feito isso: nada mais estranho do que o público sentado geometricamente banhado em luz" (Oiticica, 1971, Tombo: 0859.71):

[...] em princípio Guilherme reagiu muito: achava que o público ia se distrair pois estava iluminado, etc.; convenci a ele que estava dizendo bobagem, e que não me interessava colocar o público no escuro; pois dito e feito, o que foi mesmo legal foi esse banho de luz nas pessoas, e o modo com que Gil dialogava com elas ao cantar, por gestos, charme, olhar, etc.; houve uma onda enorme de entusiasmo por parte dos espectadores, sempre, o que me gratificou muito. (Oiticica, 1971 Tombo: 0901.71-p1)

Segundo Bablet (1968) a opção pelo apagamento da plateia é uma tática de Wagner e Appia, no início do século XX. Naquele momento, para que o espectador se concentrasse na ação dramática era necessário apagar o imenso salão disposto em forma de ferradura. Era imprescindível que a ausência de luz da sala de espetáculo apagasse também os obstáculos materiais existentes entre o espectador e a ação dramática, convergindo acima de tudo no desejo de suprimir a hierarquia social em

19 "Peter Brook's idea [Empty Space] is to faintly refer to the space in the beginning, leaving the audience to build the rest in their imagination." (Tradução nossa) 
direção ao desejo ilusionista e imersivo no drama. Naquele momento a obscuridade da plateia isolava o espectador e o desviava da preocupação de se mostrar socialmente (Bablet, 1968, p.296). Quando Oiticica assume a opção de banhar o público com a iluminação colorida há certa inversão à proposta wagneriana. A função ativa da iluminação cênica tinha mais um desdobramento. A sala disposta em arena já rompe com a estrutura hierárquica dos espectadores. Estender os limites da área dramática por meio da luz se tornava uma tática de tornar o espectador integrante da imagem total. Não se trata de mostrar-se na cena, mas de pertencer ativamente àquela experiência coletiva apelando para a sua imaginação criadora e para a sua inteligência crítica. Assim como a música e a sonoridade criada pela movimentação de Gil no ambiente cênico, a iluminação é um elemento vivo no espetáculo, age por meio da ativação aos sentidos do público e incorpora-o em cena.

Todos esses elementos são imprescindíveis para esclarecer atmosfera na qual o cantor estava inserido e a (boa) receptividade deste espetáculo em Manhattan. Várias notas foram publicadas em revistas locais, mas aquela que causou maior impacto na bilheteria foi assinada por Don Heckmann no New York Times em outubro de 1971. $\mathrm{Na}$ crítica o autor relata a temporalidade da performance de Gil relacionando-o à Bossa Nova, ao blues, ao rock e ao jazz e afirma: "Gil é um cantor de primeira classe que deveria ser ouvido por uma plateia consideravelmente maior que aquela disponível para ele na St. Clement's (Heckman, 1971, p.21)20.

Em carta para Augusto de Campos, Oiticica explicava que a repercussão da crítica fez o público crescer bastante (Oiticica, 1971, Tombo: 0901.71-p1). Para Mautner a fascinação do público acontecia "porque de repente em Manhattan, onde a barra é pesada, pesadíssima e terrível, surge uma pessoa afirmando a alegria sem ilusões, uma serenidade com movimento, movimento de ginga, dança-agilidade". Mautner ressaltava que a universalidade poética de Gilberto Gil, um cantor ainda estranho aos americanos, engendrava uma "beleza do desconhecido" e era esse fator que movia o público no show. "Eu entrei em delírio poético porque a música de Gil me arrastou para isto, Nova York me arrastou para isto, o lugar mágico que Hélio Oiticica criou me arrastou pra isto" (Mautner, 1971).

Vale ressaltar a interface que esta cenografia estabelecia àquilo que o Oiticica desenvolvia nos demais campos de trabalho. Enquanto os outros campos se lançavam como projetos muitas vezes irrealizáveis pelo alto custo financeiro ou por tamanho experimentalismo, estes trabalhos de ambientações cênicas se tornam documentos concretos das questões pelas quais o artista perpassava desde que percebeu o jogo e a ação como elementos potentes para a constituição de um trabalho. No processo de descobrimento e liberação do corpo, a música (ritmo e temporalidade) e o espaço passaram a se tornar grandes aliados e que culminam no memorável fragmento de 1979:

[...] descobri q o q faço é MÚSICA e que MÚSICA não é "uma das artes" mas a síntese da consequência da descoberta do corpo: por isso o ROCK p.ex. se tornou

\footnotetext{
${ }^{20} \mathrm{He}$ sits, with deceptive calmness, on a stool, playing a simple acoustic guitar, and providing a whole range of starling percussive effects with his lightning-quick strumming and explosive vocal accents. He can sing with a soft, sensual warmth that calls up images of warm nights at Ipanema, and he can roar with sliding blues inflections and foppish scat singing of a Ray Charles. [...] Call it bossa nova, call it Latin rock, blues or whatever, but quite simply Gil is a first class performer who should be heard by an audience 'considerably larger than the one available to him at St. Clement's. (Tradução nossa)
} 
o mais importante pra minha posta em xeque dos problemas-chave da criação (o SAMBA em q me iniciei veio junto essa descoberta do corpo no início dos anos 60: PARANGOLÉ e DANÇA nasceram juntos e é impossível separar um do outro): o ROCK é a síntese planetário-fenomenal dessa descoberta do corpo q se sintetiza no novo conceito de MÚSICA como totalidade-mundo criativa em emergência hoje: JIMI HENDRIX DYLAN e os STONES são mais importantes para a compreensão plástica da criação do q qualquer pintor depois de POLLO$\mathrm{CK}$ : a menos que queriam os artistas ditos plásticos continuar remoendo as velhas soluções pré-descoberta do corpo ao infinito: e não é o q está acontecendo de certa forma?: não seria a essa síntese MÚSICA-totalidade plástica a q teriam conduzido experiências tão diversas e radicalmente ricas na arte da primeira metade do século quanto as de MALEVICH KLEE MONDRIAN BRANCUSI?: e por que é q a experiência de HENDRIX é tão próxima e faz pensar tanto em ARTAUD?: [...]. (Oiticica, 1979, Tombo: 0057.79-p2)

Mais do que um trabalho em artes cênicas, a participação nesse show se tornou um documento que materializa a interlocução poética existente entre Gilberto Gil e Hélio Oiticica. A idealização do espaço-penetrável de áreas de luz em consonância com as músicas do repertório de Gilberto Gil evidencia a função social do ambiente cênico e enaltecem sob a condição temporal, pictórica, cinética, vivencial e performativa da obra de arte tão caros às "obras ambientais" projetadas por Oiticica. Antes de ser uma eloquência visual para o deleite do espectador estes ambientes agem como elemento de qualidade sintética e heterogênea, criam dissensos à realidade e agem como dispositivos para a ação, para a experiência. Na cenografia de Oiticica não se trata de "tapar" o edifício como o faz a tapadeira ou mesmo o telão pintado, mas conferir ao ator-espectador outra relação com a matéria, com espaço e com a ação cênica. Há o entendimento de que a encenação é na verdade uma "experiência" - livre e descompromissada. Trata-se de fornecer ferramentas ao sujeito para intervir neste ambiente, tornar-se agente, tornar-se corpo, ator, co-criador. 


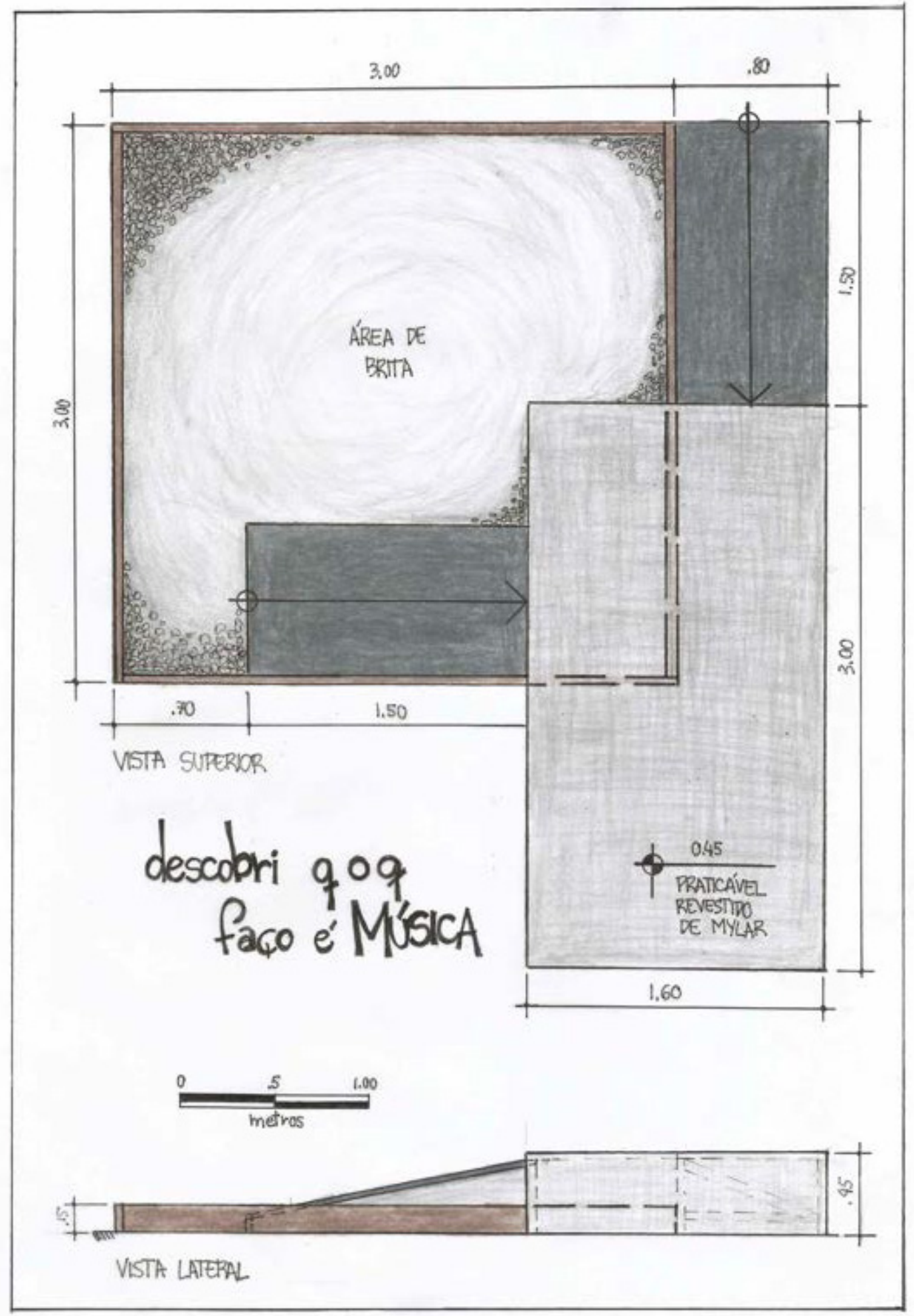

Planta baixa da cenografia desenvolvida pela autora com medidas estimadas a partir das fotografias do Show de Gilberto Gil in concert e planta da St. Clement' Church para estudo da estrutura. Arquivo: pessoal

\section{Referências}

ARONSON, Arnold. The history and theory of Environmental Scenography. New York University. Ann Arbor, Michigan: UMI Research Press, 1981 (1aed. 1977). 
BABLET, Denis. A luz no teatro. In: REDONDO JUNIOR. (Org.) Teatro e a sua Estética. Volume II Lisboa: Arcádia, 1968. p.289-309.

BASUALDO, Carlos. (Org.) Tropicália: uma revolução na cultura brasileira. São Paulo: Cosac \& Naify, 2007.

BAUGH, Christopher. Theatre, Performance and Technology: the development of scenography in the twentieth century. Palgrave. Macmillan: Theatre \& Performance Pratices: 2005

BENJAMIN, Walter. A tarefa do tradutor, de Walter Benjamin: quatro traduções para o português. Trad. Fernando Camacho. Cadernos Viva Voz Belo Horizonte Fale/UFMG 2008.

Disponíveis em: www.letras.ufmg.br/site/publicacoes/publicacoes.htm Acesso em: 15 set. 2016.

CAGE, John. De segunda a um ano. Trad. Rogério Duprat; revista por Augusto de Campos. Rio de Janeiro: Cobogó, 2013.

CAMPOS, Augusto. Balanço da Bossa e outras bossas. São Paulo: Perspectiva. $19742^{\underline{a}}$ ed. Col. Debates.

COSTA, Gal. Divino, Maravilhoso. Texto publicado no site oficial da cantora, escrito em 29/06/2005. Acesso em: 10 jan. 2016. Disponível em:

http://www.galcosta.com.br/sec_textos_list.php?page=1\&id=22\&id_type=2

FAVARETTO, Celso F. A Invenção de Hélio Oiticica. São Paulo: EDUSP, 1992.

FIGUEIREDO, Luciano (Org.). Cartas 1964-1974: Lygia Clark \& Hélio Oiticica. Rio de Janeiro, Ed UFRJ, 1998.

(Org.). Aspiro ao Grande Labirinto: Helio Oiticica. Rio de Ja-

neiro: Rocco, 1986.

FOUCAULT, Michel. O corpo utópico; As heterotopias. Trad.: Selma Tannus Muchail. São Paulo: n-1 Edições, 2013.

Of Other Spaces, Heterotopias. Foucault, Michel. "Of Other

Spaces, Heterotopias." Architecture, Mouvement, Continuité 5 (1984): 46-49. Publicação Original: Conférence au Cercle d'études architecturales, 14 mars 1967 Acesso em: 02 dez. 2014. Disponível em:

http://foucault.info/documents/heteroTopia/foucault.heteroTopia.en.html.

HECKMAN, Don. Gilberto Gil Plays And Sings Program Evocative of Brazil. The New York Times 9 de outubro de 1971 pg. 21 
JONES, Robert Edmond. A um jovem decorador. Luz e sombra no teatro. In: JUNIOR, Redondo. (Org.) Teatro e a sua Estética. V. II Lisboa: Arcádia, 1968. p.311-333.

KANDINSKY, Wassily. Do espiritual na arte e na pintura em particular. Trad. Álvaro Cabral. 2ª Ed. - São Paulo: Martins Fontes, 1996.

LECAT, Jean-Guy. In: Hirvikoski, Reija. Space is Scenography. http://www.reijahirvikoski.net/articles/space-is-scenography Acesso em 18/01/2016. Publicado originalmente em Finnish in The Finnish Theatre Magazine: Teatterilehti 5/2006.

MENDES, Lucas. Revista Manchete № 1018, 23 de outubro de 1971. Fotos de Gerald Davis (da nossa sucursal em Nova lorque). P. 111-112

MAUTNER, Jorge. Jornal o Pasquim. Um verdadeiro saco de ratos. № $122,2-8$ de novembro de 1971. Rio de Janeiro. 1971

RANCIÈRE, Jacques. O espectador emancipado. Trad. Ivone C Benedetti. São Paulo: Martins Fontes, 2012.

ZAPPA, Regina. Gilberto Bem Perto 2013. Versão digital Kindle.

\section{Textos De Hélio Oiticica}

Carta para Augusto de Campos em 16 de outubro de 1971 Tombo: 0901.71. Disponível in: Arquivo H.O. Data: 16/10/71 Local: Nova York / Nova York / Estados Unidos. 1971

Carta para Haroldo de Campos em 19 de outubro de 1971. Tombo: 0859.71. Disponível in: Arquivo H.O. Data: 19/10/71 Local: Nova York / Nova York / Estados Unidos. 1971

Carta para Luiz Carlos Maciel em 24 de setembro de 1971. Tombo: 0904.71-p1. Disponível in: Arquivo H.O. Arquivo H.O. Data: 24/10/71 Local: Nova York / Nova York / Estados Unidos. 1971

Carta para Roberta Oiticica. 18 de novembro de 1971. Tombo 0846.71. Disponível in: Arquivo H.O. Data: 18 nov. 71 Local: Nova York / Nova York / Estados Unidos. 1971.

Carta para Silviano [Santiago] de 15 de setembro de 1971. OITICICA, H. 1971: Tombo 0906.71. Disponível in: Arquivo H.O. Data: 15/11/71 Local: Nova York / Nova York / Estados Unidos. 1971

Carta para Vera Pedrosa setembro de 1971 Tombo: 0759.71. Disponível in: Arquivo H.O. Data: 10/12/71 Local: Nova York / Nova York / Estados Unidos. 1971 
DE HÉLIO OITICICA PARA BISCOITOS FINOS Número de Tombo: 0057.79. Disponível in: Arquivo H.O. Local: Rio de Janeiro / Rio de Janeiro / Brasil. 1979

GILBERTO GIL Número de Tombo: 0216.71. Disponível in: Arquivo H.O. 1971 Local: Nova York / Nova York / Estados Unidos. 1971

RAP IN PROGRESS Hélio e Carlos Vergara OITICICA, H. 1973. Tombo: 0504.73. Disponível in: Arquivo H.O. Data: 28/Out/73 Local: Nova York / Nova York / Estados Unidos. 1973

Recebido em: 21/11/2017 Aprovado em: 11/03/2018 